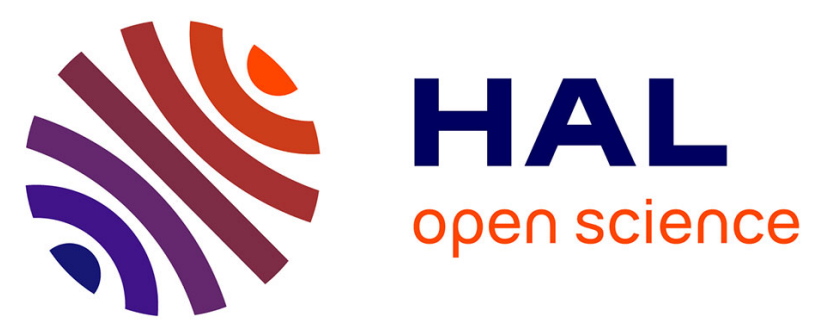

\title{
Numerical study of soot formation in laminar coflow methane/air diffusion flames doped by n-heptane/toluene and iso-octane/toluene blends
}

\author{
J.-L. Consalvi, F Liu, M Kashif, Guillaume Legros
}

\section{To cite this version:}

J.-L. Consalvi, F Liu, M Kashif, Guillaume Legros. Numerical study of soot formation in laminar coflow methane/air diffusion flames doped by n-heptane/toluene and iso-octane/toluene blends. Combustion and Flame, 2017, 180, pp.167 - 174. 10.1016/j.combustflame.2017.03.002 . hal-01524451

\section{HAL Id: hal-01524451 \\ https://hal.sorbonne-universite.fr/hal-01524451}

Submitted on 18 May 2017

HAL is a multi-disciplinary open access archive for the deposit and dissemination of scientific research documents, whether they are published or not. The documents may come from teaching and research institutions in France or abroad, or from public or private research centers.
L'archive ouverte pluridisciplinaire HAL, est destinée au dépôt et à la diffusion de documents scientifiques de niveau recherche, publiés ou non, émanant des établissements d'enseignement et de recherche français ou étrangers, des laboratoires publics ou privés. 


\title{
Numerical study of soot formation in laminar coflow methane/air
}

\section{diffusion flames doped by $n$-heptane/toluene and iso-}

\section{octane/toluene blends}

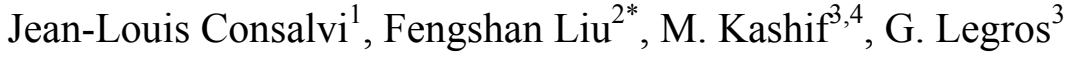 \\ ${ }^{1}$ Aix-Marseille Université, CNRS, IUSTI UMR 7343, 5 rue E. Fermi, 13013 Marseille, \\ France \\ ${ }^{2}$ Measurement Science and Standards, National Research Council of Canada, 1200 Montreal \\ Road, Ottawa, Ontario, Canada K1A 0R6 \\ ${ }^{3}$ Sorbonne Universités, UPMC Univ Paris 06, CNRS, UMR 7190 Institut Jean le Rond \\ d'Alembert, F-75005 Paris, France \\ ${ }^{4}$ University of Central Punjab, Mechanical Department, Faculty of Engineering, 1 Khayaban- \\ e-Jinnah, Johar Town, Lahore, Pakistan
}

\section{Abstract:}

The laminar coflow nitrogen-diluted methane/air diffusion flames doped with a small amount of $n$-heptane/toluene and iso-octane/toluene binary mixtures, investigated experimentally by Kashif et al. [Combust. Flame 162 (2015) 1840-18476], were simulated numerically by using a detailed reaction mechanism and a sectional polycyclic aromatic hydrocarbon (PAH)-based soot model. The numerical model provides results in reasonable qualitative agreement with the experimental data by using the same chemical mechanism, the same soot model, and the same set of constants employed successfully in a previous study to model the effects of $n$ heptane/iso-octane doping, demonstrating that this overall model is promising to model soot formation in gasoline flames. Soot production is enhanced monotonically with increasing the 
toluene content in either the n-heptane/toluene or iso-octane/toluene doping fuel mixture. The increase in benzene and pyrene production displays a non-monotonic and synergistic response to the increase in toluene content. These numerical results are consistent with available experimental results as far as the trends in the effects of increasing the toluene content are concerned. Model results show that the dominant pathways responsible for the synergistic effects on benzene and pyrene production are respectively $\mathrm{C}_{6} \mathrm{H}_{5} \mathrm{CH}_{3}$ (n-heptane) $+\mathrm{H} \leftrightarrow \mathrm{A} 1$ (benzene) $+\mathrm{CH}_{3}$ and $\mathrm{A} 3-\left(\mathrm{C}_{14} \mathrm{H}_{9}\right)+\mathrm{C}_{2} \mathrm{H}_{2} \leftrightarrow \mathrm{A} 4$ (pyrene) $+\mathrm{H}$.

Key words : Laminar coflow diffusion flame; Gasoline Surrogate; Toluene reference fuels; PAH-based soot model; Synergistic effects. 


\section{Introduction}

Emissions of soot produced during incomplete combustion from various combustion systems, such as internal combustion engines and biomass burning, into the atmosphere have become a serious environment and health concern worldwide $[1,2]$. The transportation sector is largely responsible for black carbon emissions in developed countries and most of the on-road vehicles are powered by gasoline engines. The newly developed gasoline direct injection (GDI) engines offer better fuel economy by about 5 to $15 \%$ as compared to the traditional port fuel injection (PFI) gasoline engines, which helps lower $\mathrm{CO}_{2}$ emissions. Unfortunately, GDI engines emit much more soot due to the stratified combustion mode in such engines. It is therefore desirable to understand the effects of various physical and chemical factors on soot formation to reduce soot emissions. Although it is important to investigate the effects of these factors on soot emissions from GDI engines, it is challenging to isolate the influence of a particular factor, such as fuel chemistry, on soot formation, as the high sensitivity of soot emissions from a GDI engine to various engine parameters can mask the effect of this particular factor on soot formation. In order to circumvent this drawback, well-controlled laminar diffusion flames have been often used [3-7].

Gasoline consists of hundreds of aliphatic and aromatic hydrocarbon species. In order to make CFD analysis of gasoline engine performance and pollutants emissions tractable, it is necessary to develop surrogate fuel models, i.e., a simple mixture of few hydrocarbon compounds formulated in such a way that it has similar physical, chemical, and combustion characteristics as the real fuel. The primary constituents of gasoline are $n$-heptane $\left(\mathrm{nC}_{7} \mathrm{H}_{16}\right)$, iso-octane $\left(\mathrm{iC}_{8} \mathrm{H}_{18}\right)$ and toluene $\left(\mathrm{C}_{6} \mathrm{H}_{5} \mathrm{CH}_{3}\right)$ [8]. The binary mixtures of $n$-heptane and isooctane are referred to as the primary reference fuels (PRF) for octane ratings. A binary mixture of $n$-heptane and iso-octane corresponds to a particular octane number or octane 
rating. Most gasoline surrogates are composed of toluene $\left(\mathrm{C}_{6} \mathrm{H}_{5} \mathrm{CH}_{3}\right)$, iso-octane $\left(\mathrm{i}-\mathrm{C}_{8} \mathrm{H}_{18}\right)$, and $n$-heptane $\left(\mathrm{C}_{7} \mathrm{H}_{16}\right)$, also known as toluene reference fuels (TRFs) [8-12]. This has motivated the development of full and skeletal kinetic mechanisms for gasoline surrogates involving polycyclic aromatic hydrocarbons (PAHs), which are a prerequisite to model soot production [3, 12-14].

Several experimental studies based on well-controlled laminar diffusion flames and aiming to understand soot formation in gasoline surrogates were reported. The sooting tendencies of gasoline, diesel, jet-A fuels and their surrogates were experimentally investigated in a laminar coflow heated methane/air diffusion flame at atmospheric pressure by doping methane with a small amount of vaporized liquid fuels (2200-2300 ppm) [4]. Kashif et al. conducted similar experiments to characterize the fuel sooting propensity of binary mixtures of $n$-heptane and iso-octane, $n$-heptane and toluene, and iso-octane and toluene $[5,6]$. They considered laminar $\mathrm{CH}_{4} /$ air coflow diffusion flames doped with these vaporized binary mixtures. The sooting tendency of these binary mixtures was determined by considering the Yield Sooting Indices (YSI) based on n-hexane and benzene. The soot production tendency of PRF was found to increase linearly with the volume fraction of iso-octane [5]. In contrast, the sooting tendency of $n$-heptane/toluene and iso-octane/toluene mixtures was found to increase in a non-linear and monotonic fashion with the toluene mole fraction [6]. In other words, the peak soot volume fraction in these binary mixture doped flames was found to be higher than that from a simple linear-per-volume model. In addition, the experimental data showed a larger degree of non-linear behavior in iso-octane/toluene mixtures than that in $n$-heptane/toluene mixtures [6]. The non-linear variation of the peak soot volume fraction with toluene content in the binary mixtures is consistent with the experimental study of Choi et al. [3] conducted in $n$ heptane/toluene and iso-octane/toluene mixtures in soot formation/soot oxidation counterflow 
diffusion flames. Moreover, the experimental results of Choi et al. [3] showed that there exists a synergistic effect in $\mathrm{PAH}$ production in these mixtures, especially in iso-octane/toluene mixture, but not in soot formation. The synergistic effect is defined in a consistent manner with previous studies on soot and PAH formation and refers to the case when a mixture fuel (containing two hydrocarbons) can produce more PAH and/or soot as compared to the individual pure fuels $[3,14-18]$.This study intends to gain fundamental understanding into the effects of fuel chemistry of a TRF gasoline surrogate on soot formation. In particular, the focus is on the chemical kinetic interactions between iso-octane and toluene and between $n$ heptane and toluene with respect to PAH and soot formation. This study is complementary to the previous studies $[5,19]$, where soot formation in laminar coflow methane/air diffusion flames doped with iso-octane and $n$-heptane blends was conducted experimentally and numerically, to gain a more comprehensive understanding of soot formation in diffusion flames fueled with binary mixtures of TRF components.

\section{Experiments}

The laminar coflow diffusion flames studied experimentally by Kashif and coworkers [6] are simulated. In these experiments, measurements of soot volume fraction distribution were conducted in laminar coflow nitrogen-diluted methane diffusion flames doped with binary mixtures of either $n$-heptane and toluene or iso-octane and toluene at atmospheric pressure. The oxidizer is pure air. The composition of the binary mixture is identified by the volume fraction of toluene, $X_{\text {tol }}$, which is varied between 0 (pure n-heptane or iso-octane) and 1 (pure toluene). The burner consists of two concentric steel tubes of $11 \mathrm{~mm}$ (for fuel) and 102-mm (for oxidizer) inner diameter, respectively. The carrier gas, with a composition of $50 \%$ methane $/ 50 \%$ nitrogen by volume, and the dopant (binary mixtures of $n$-heptane/toluene or iso-octane/toluene) flow through the central fuel tube and their volumetric flow rates are kept 
at $400 \mathrm{~cm}^{3} / \mathrm{min}$ and $10.13 \mathrm{~cm}^{3} / \mathrm{min}$ (at $20^{\circ} \mathrm{C}$ and $1 \mathrm{~atm}$ ), respectively. This leads to a mole fraction of the vaporized binary fuel mixture of $2.47 \times 10^{-2}$ in the fuel stream. The fuel line is maintained at about $423 \mathrm{~K}$ to prevent the condensation of the dopant.

The distribution of soot volume fraction was measured by a 2D light extinction measurement (LEM) technique at $645 \mathrm{~nm}$. The value of the soot absorption refractive index function, $E(m)$, corrected to take into account the contribution of scattering $\left(\left(1+\alpha_{s a}\right) E(m)\right.$, where $\alpha_{\mathrm{sa}}$ is the relative contribution of scattering to extinction) is taken equal to 0.28 for $n$-heptane and isooctane and 0.308 for toluene [6]. For binary mixtures of $n$-heptane/toluene and isooctane/toluene, this value is assumed to vary linearly with $X_{\text {tol }}$. It should be pointed out that varying the refraction index from 0.28 to 0.308 as $X_{\text {tol }}$ varies from 0 to 1 modifies the measurements of soot volume fraction by only about $10 \%$ which significantly less than the experimental uncertainty related to the value of $E(m)$ itself. Further details of the experimental setup and soot measurements using the LEM technique can be found in $[5,6]$.

\section{Numerical model}

The governing equations and the solution method have been given in previous studies $[7,19$, 20] and will be described only briefly. The numerical model solves the conservation equations for mass, momentum, gas-phase species mass fraction, and energy in the low Mach number formulation and in axisymmetric coordinates by using a finite volume method and the SIMPLE algorithm. Additional transport equations for sectional soot aggregate and primary particle number densities are solved to describe the soot particle dynamics [7]. The divergence of the radiative flux was computed by the discrete ordinate method coupled to a statistical narrow-band-correlated k-based wide-band model for properties of $\mathrm{CO}, \mathrm{CO}_{2}$, and $\mathrm{H}_{2} \mathrm{O}[21]$. The spectral absorption coefficient of soot was obtained by Rayleigh's theory. 
The reaction mechanism was assembled by merging the PAH formation and growth submechanism developed at DLR $[22,23]$ to the non-PAH part of a shortened version of the mechanism developed by Raj et al. [14] for gasoline surrogate fuel involving mixtures of nheptane, iso-octane, and toluene. The shortened version of Raj et al. mechanism was described in [24] and the assembled hybrid mechanism for gasoline surrogate based on the DLR PAH sub-mechanism and the shortened Raj et al. non-PAH mechanism was described in detail in [19]. The final mechanism consists of 175 chemical species and 1175 reactions. The validation of this mechanism has been documented by Raj et al. [14]. The replacement of the original PAH sub-mechanism of Raj et al. [14] by that of DLR is not expected to alter its performance in flame modelling other than concentrations of PAHs, which are in general very low.

The fixed sectional soot model has been used and described in several previous studies, e.g. [20]. The range of soot aggregate mass is divided into a number of discrete sections, each with a prescribed representative mass [20]. In each section, all the soot aggregates are assumed to be identical and to be comprised of equally sized spherical primary particles and to have a fractal dimension of 1.8. The evolution of each section is governed by two transport equations for the number densities of soot aggregate and primary particle [20]. The incipient soot particles are assumed to be spherical and belong to the first section. As in previous studies [7, 19-21], 35 sections were used with a spacing factor of 2.35. Coagulation terms are calculated using the same method given in Ref. 25 . The soot kinetics model is based on the work of Appel et al. [26]. Soot inception is assumed to be the result of collision of two pyrene molecules (A4). All the A4-A4 collision leads to the formation of a soot particle. Surface growth and oxidation are assumed to follow the HACA mechanism, with the model parameters taken as those prescribed in the original version [26], except the steric factor $\alpha$. 
Based on our recent study using the same assembled hybrid gasoline surrogate mechanism for modelling soot formation in laminar coflow methane/air diffusion flames doped with isooctane and n-heptane blends [19], the same steric factor of $\alpha=0.1$ was also used in the present calculations. Soot surface growth through PAH surface condensation was also taken into account and modelled as the condensation of A4 molecules colliding with soot aggregates [26]. A PAH condensation efficiency is introduced and assumed to be 0.5 [20].

It should be pointed out that the sub-models for gas-phase chemistry and soot production and the set of model parameters are all the same as those considered in Ref. 19. They were found to provide a reasonably good description of soot production in laminar coflow diffusion flames of methane doped with different blends of $n$-heptane and iso-octane. As a consequence, the present study presents additional more challenging cases in the validation of these models for predicting soot production in methane doped flames with other binary TRF components involving toluene.

Numerical calculations were performed according to the experimental conditions of Kashif et al. [6] in a domain of $9.82 \mathrm{~cm}(z) \times 4.71 \mathrm{~cm}(r)$ using $210(z) \times 88(r)$ control volumes. A nonuniform mesh was used with a resolution of $0.01 \mathrm{~cm}$ in the $\mathrm{r}$-direction and $0.01375 \mathrm{~cm}$ in the z-direction near the burner exit. At the fuel inlet a parabolic velocity profile was considered with a mean stream velocity of $7.19 \mathrm{~cm} / \mathrm{s}$. At the oxidizer stream, the inlet temperature was set at $293 \mathrm{~K}$ and a uniform velocity of $12.32 \mathrm{~cm} / \mathrm{s}$ was assigned.

\section{Results and discussion}

Figure 1 compares the computed temperature distributions in the $n$-heptane/toluene doped flames of different $X_{\text {tol }}$. A similar behavior is also observed for iso-octane/toluene doped flames. Increasing the toluene percentage in the binary n-heptane/toluene or iso- 
octane/toluene doping mixture has only a minor effect on the total carbon flow rate, the carbon-to-hydrogen ratio, or the oxidizer-to-fuel mass ratio. As a consequence, the peak flame temperature, which occurs in the annular region low in the flame around $\mathrm{z}=2 \mathrm{~cm}$, and the stoichiometric flame height, defined as the axial location of the maximum temperature, are only slightly decreased and increased, respectively, as more toluene is added to the $n$ heptane/toluene blend. The residence times of a fluid parcel to reach a given height in these flames are therefore expected to be nearly the same. Although the peak flame temperature is only slightly lowered (by $11 \mathrm{~K}$ ), the temperatures in the centerline region around the flame tip are actually significantly reduced with increasing $X_{\text {tol }}$ from 0.2 to 0.8 . This is explained by the enhanced radiative heat loss associated with the increase in soot loading with increasing $X_{\text {tol }}$ shown below.
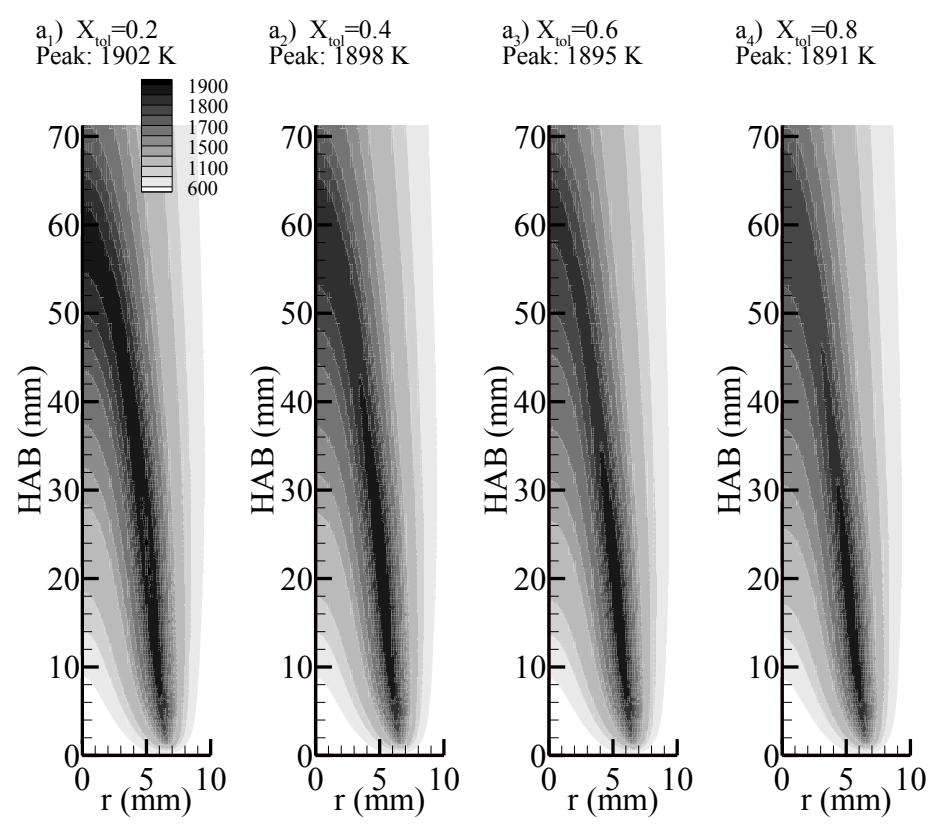

Figure 1. Distributions of temperature (in K) in n-heptane/toluene doped flames for different $X_{\text {tol }}$. 
The distributions of computed soot volume fraction are compared with those of experimental measurement in both the $n$-heptane/toluene doped and iso-octane/toluene doped flames in Fig. 2. The experimental data (top plots in Fig. 2) show that, in both binary mixtures, the increase in the percentage of toluene in the mixture leads to a monotonic increase in the peak soot volume fraction i.e., in soot production. However, there is no synergistic effect in soot formation in these binary mixture doped flames. In addition, for a given value of $X_{\text {tol }}$ the isooctane/toluene doped flames, top right plots in Fig. 2, produce more soot than the $n$ heptane/toluene doped flames, top left plots in Fig. 2. The higher soot volume fractions in the iso-octane/toluene doped flames are somewhat expected, since the sooting propensity of isooctane is known to be higher than that of $n$-heptane $[3,5,19]$. The experimental results of Kashif et al. [6] obtained in laminar co-flow diffusion flames, shown in the top panels of Fig. 2, are consistent with those of Choi et al. [3] obtained in counterflow diffusion flames. The experimental soot volume fractions also suggest that the luminous flame height behaves differently from the stoichiometric flame height as $X_{\text {tol }}$ is increased. The increase in the luminous flame height with increasing $X_{\text {tol }}$ is related to the increase in soot loading, which requires more time to be fully oxidized. Overall, the trends in the numerical results shown in the bottom panels of Fig.2 agree qualitatively well with the experiments, i.e., the peak soot concentration increases with increasing $X_{\text {tol }}$ and is higher in iso-octane/toluene doped flames than in $n$-heptane/toluene doped ones. The predicted "luminous flame" height increases also with $X_{\text {tol }}$, though the rate of increase seems to be lower than that observed experimentally. The main deficiency in the predicted soot volume fraction distributions lies in the significant underestimation in the centreline region of the upper portion of the flames, which has been frequently observed in previous numerical studies of soot formation in laminar coflow diffusion flames $[7,19]$. The predicted peak soot volume fraction occurs in the annular region of the flame wing, regardless of the toluene content in the doping mixture. On the other hand, 
the measured soot volume fraction in these liquid fuel doped methane/air flames displays high values in the flame centreline region, which agrees with several recent experimental measurements of soot volume fraction distribution in laminar coflow diffusion flame fuelled with vaporized liquid fuels [4-7]. The occurrence of high soot concentrations in the flame centreline region is an interesting feature of liquid hydrocarbon fuels. The deficiency in the predicted soot volume fraction distribution is highly likely caused by the oversimplified assumption that soot nucleation is initiated by collision of two pyrene molecules, whereas in reality soot nucleation perhaps involve multiple PAHs [12,27,28]

Although the predicted peak soot volume fractions are about $30 \%$ lower than the measured peak values, the discrepancy in the peak soot volume fraction between prediction and experiment is likely smaller if one realizes that the employed value of $E(\mathrm{~m})(0.28)$ in the experiments [6] is about $30 \%$ lower than the recently recommended value of 0.35 for soot $E(m)$ in the visible spectral region by Coderre et al. [29]. 


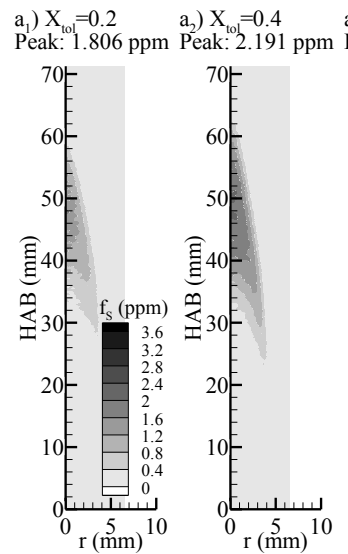

$\begin{array}{ll}\left.\mathrm{a}_{3}\right) \mathrm{X}_{\text {to }}=0.6 & \left.\mathrm{a}_{4}\right) \mathrm{X}_{\mathrm{to}}=0.8 \\ \text { Peak: } 2.942 \text { ppm Peak: } 3.408 \text { ppm }\end{array}$
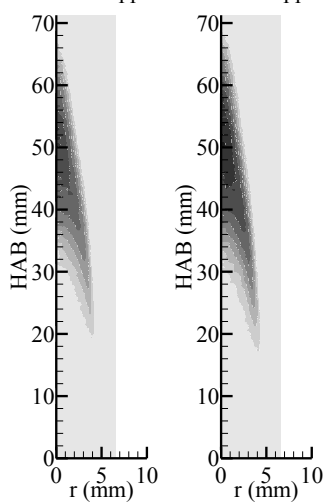

$\left.\mathrm{b}_{1}\right) \mathrm{X}_{\mathrm{to}}=0.2$

$\left.\mathrm{b}_{2}\right) \mathrm{X}_{\mathrm{to}}=0.4$

$\begin{array}{ll}\left.b_{3}\right) X_{\text {to }}=0.6 & \left.b_{4}\right) X_{\text {to }}=0.8 \\ \text { Peak: } 2.398 \text { ppm } & \text { Peak: } 2.715 \text { ppm }\end{array}$
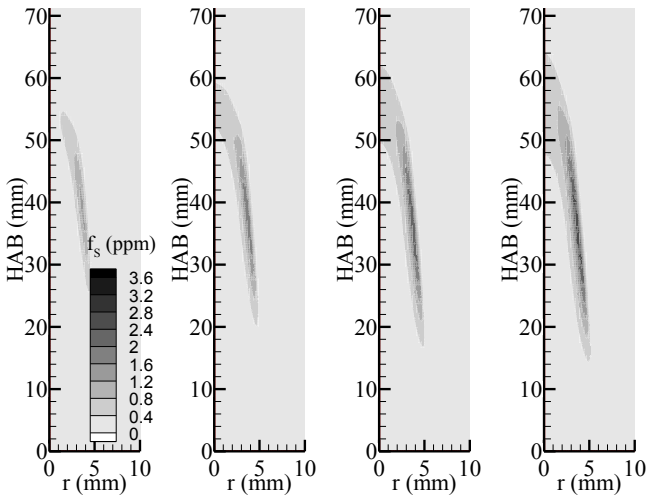

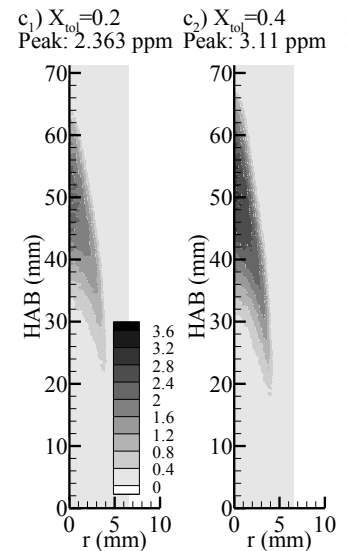

$\begin{array}{ll}\left.\mathrm{c}_{3}\right) \mathrm{X}_{\mathrm{to}}=0.6 & \left.\mathrm{c}_{4}\right) \mathrm{X}_{\mathrm{to}}=0.2 \\ \text { Peak: } 3.548 \text { ppm } & \text { Peak: } 3.634 \mathrm{ppm}\end{array}$
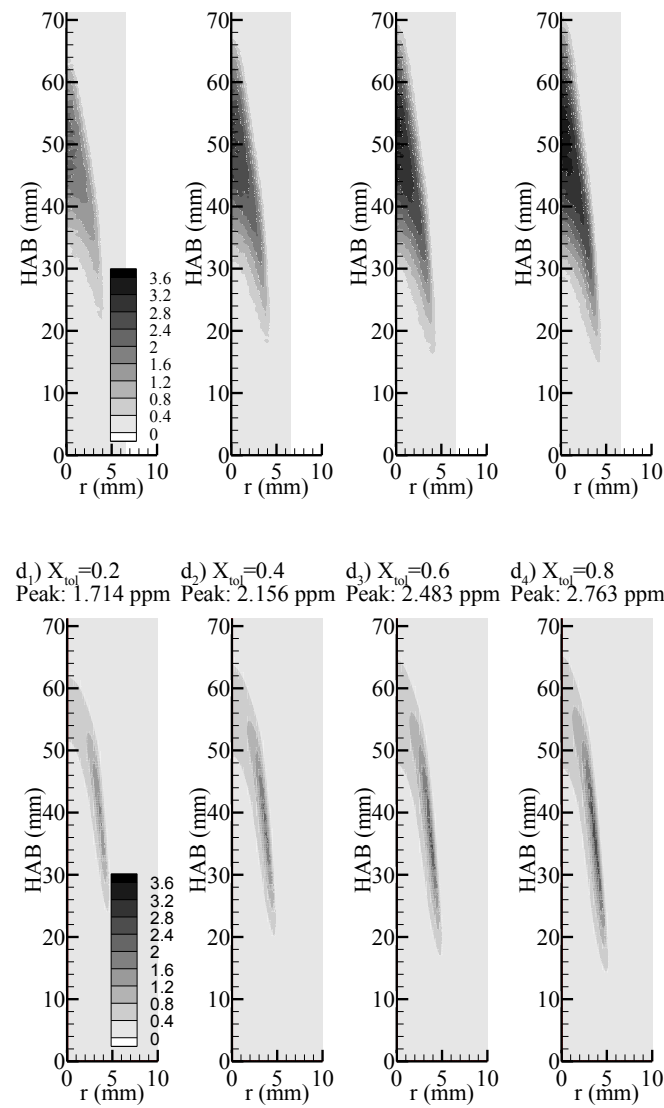

$\left.\left.\mathrm{d}_{3}\right) \mathrm{X}_{\mathrm{to}}=0.6 \quad \mathrm{~d}_{4}\right) \mathrm{X}_{\mathrm{to}}=0.8$

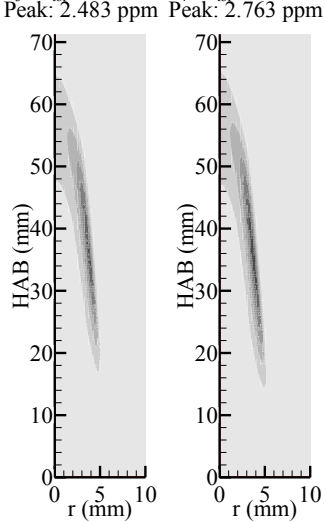

Figure 2. Measured (top row) and computed (bottom row) distributions of soot volume fraction in $n$-heptane/toluene doped flames, (a) and (b) (left column), and in isooctane/toluene doped flames, (c) and (d) (right column), for $X_{\text {tol }}$ between 0.2 and 0.8 .

The variation of the peak soot volume fraction with $X_{\text {tol }}$ is plotted in Fig. 3a. As mentioned previously, $f_{S, \max }$, increases monotonically with $X_{\text {tol }}$ in both the n-heptane/toluene and isooctane/toluene doped flames. The experimental variations are clearly non-linear. It appears that adding toluene to $n$-heptane or iso-octane produces more soot than expected from the simple linear-by-volume model [6]. The computed $f_{S, \max }$ follows a similar trend to the experiments, increasing monotonically with $X_{\text {tol }}$ and exhibiting a similar non-linear behaviour, albeit the overall variation with $X_{\text {tol }}$ is somewhat less significant than that of measurements, Fig. 3(a). 

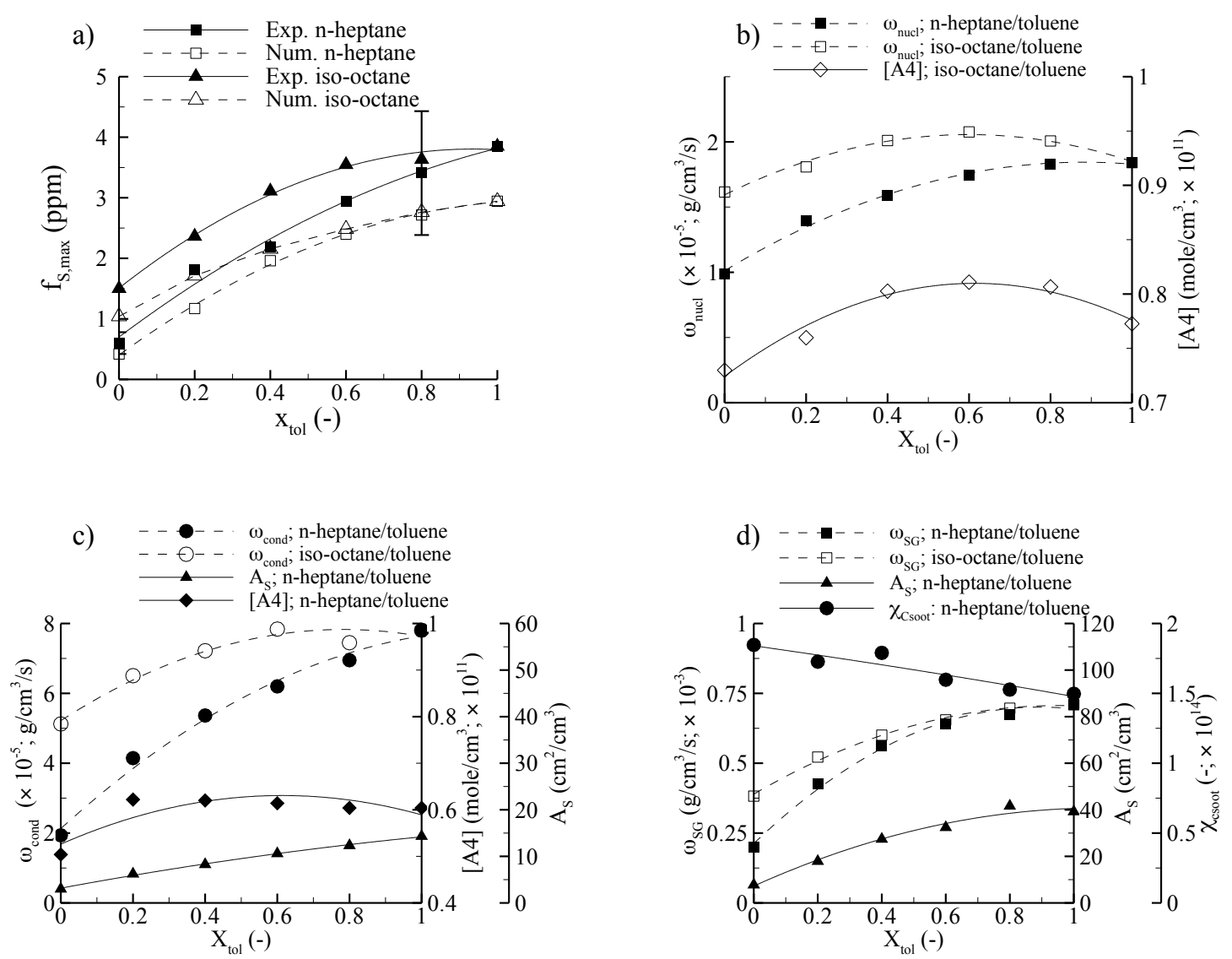

Figure 3. Variations of the peak soot volume fraction and other soot related quantities with

$X_{\text {toll }}$ (a) the measured and predicted peak soot volume fraction, (b) the computed peak nucleation rate and A4 molar concentration, (c) the computed peak condensation rate, A4 molar concentration, and soot surface area density, and (d) the computed peak HACA surface growth rates, soot surface area density, and the number of de-hydrogenated sites.

A metric is defined to quantify the degree of non-linearity based on the relative departure from the linear behaviour, $E_{r}$, between the actual values, $\phi_{a}$, and the values expected from the linear-by-volume model, $\phi_{l}\left(\phi_{l}\left(X_{t o l}\right)=\left[\phi_{a}\left(X_{t o l}=1\right)-\phi_{a}\left(X_{t o l}=0\right)\right] \times X_{t o l}+\phi_{a}\left(X_{t o l}=0\right)\right)$ :

$E_{r}=\sum_{X_{t o l}=0.2}^{X_{t o l}=0.8} \frac{\phi_{a}\left(X_{t o l}\right)-\phi_{l}\left(X_{t o l}\right)}{\phi_{a}\left(X_{t o l}\right)}$ 
where $\phi$ is any quantity of interest, such as soot volume fraction or soot surface growth rate. $E_{\mathrm{r}}$ is positive when the actual quantity is higher than the value from the linear-by-volume model, i.e., $\phi_{a}\left(X_{t o l}\right)>\phi_{l}\left(X_{t o l}\right)$. The larger the value of $E_{\mathrm{r}}$ is, the stronger the non-linearity in $\phi$ is. The determination of $E_{\mathrm{r}}$ in the case of the experimental data of peak soot volume fraction shows that the non-linearity is stronger in iso-octane/toluene doped flames $\left(E_{r}=1.07\right)$ than that in $n$-heptane/toluene doped flames $\left(E_{\mathrm{r}}=0.59\right)$. However, the predicted soot volume fractions show that the non-linearity of the peak soot volume fraction in the $n$-heptane/toluene doped flames $\left(E_{r}=0.63\right)$ is higher than that in the iso-octane/toluene doped flames $\left(E_{r}=\right.$ 0.37). It is noticed that this disagreement between the model and experiments merely reflects the fact that the predicted peak soot volume fraction in n-heptane/toluene doped flames has a larger departure from the linear increase with $X_{\text {tol }}$ than that in iso-octane/toluene doped flames shown in Fig. 3(a), while the opposite is true in the measurements. The departure from the linear variation with $X_{\text {tol }}$, i.e., non-linearity, is a higher-order effect. What is much more important is the fact that the model correctly predicts the main features of the results shown in Fig. 3(a): the peak soot volume fractions increase with increasing $X_{\text {tol }}$ and are higher in isooctane/toluene doped flames than those in n-heptane/toluene doped flames, in agreement with the experimental measurements.

Although there are deficiencies in the current PAH/soot models, as reveled in the mismatch between the modeled and measured peak soot volume fraction locations and the different degrees of non-linearity in the peak soot volume fraction with respect to $X_{\text {tol }}$ variation, it is believed that the model is still capable of identifying the dominant pathways responsible for the enhanced production in PAH and soot with increasing $X_{\text {tol }}$ based on the overall qualitative agreement between the predicted and measured soot volume fractions shown in Figs. 2 and $3(\mathrm{a})$

The mechanisms responsible of the synergistic effects are analysed at the locations where soot nucleation, PAH condensation, and surface growth through HACA rates peak. It is recognized 
that these peak soot formation rates occur at different locations in a given flame and even differ from those in the experiments. However, such analysis is followed as a convenient way to identify the main mechanisms responsible for the non-linear responses of soot nucleation and surface growth through HACA and PAH condensation. The maximum rates for inception, $\dot{\omega}_{\text {nucl }}$, and PAH condensation, $\dot{\omega}_{\text {cond }}$, occur along the flame centreline; however, the peak for surface growth by $\mathrm{C}_{2} \mathrm{H}_{2}$ addition through $\mathrm{HACA}, \dot{\omega}_{S G}$, appears along the flame wing. The maximum rates for inception, PAH condensation, and surface growth through HACA are plotted in Figs. 3(b), 3(c) and 3(d), respectively. Model results show that the HACA surface growth process dominates the mass growth of soot particles. Figures 3(c)and 3(d) show that the peak HACA surface growth rates are approximately an order of magnitude higher than the peak PAH condensation rates, which are in turn higher than the peak inception rates, shown in Fig. 3(b), by a factor of about 3 to 4 . The three soot formation rates are lower in the pure $n$ heptane or pure iso-octane $\left(X_{t o l}=0\right)$ doped flames than those in the pure toluene $\left(X_{\text {tol }}=1\right)$ doped ones. Between these two limits they increase monotonically with $X_{\text {tol }}$, with the exception of the peak nucleation rate in iso-octane/toluene doped flames, which exhibits a synergistic effect and reaches a maximum at $X_{t o l}=0.6$, Fig. 3(b). In addition, all the soot formation rates display a non-linear relationship with $X_{\text {tol }}$ This suggests that all the three modes of soot mass growth, especially the HACA surface growth which contributes for most of the soot production, are likely responsible for the non-linear behaviour of $f_{S, \max }$ shown in Fig. 3(a).

The temperatures, $T$, were found to remain nearly constant at the locations where soot reaction rates peak as $X_{\text {tol }}$ increases. As a consequence, temperature plays a negligible role in how these soot formation rates vary with the toluene content in the binary doping fuel mixtures. In addition, the pathways responsible for the non-linear behaviour of soot formation 
rates were found to be the same in both $n$-heptane/toluene and iso-octane/toluene doped flames. As a consequence, to facilitate the understanding of results shown in Figs. 3(b), 3(c), and 3(d), the following discussion will be focused on only one blend (either nhepthane/toluene or iso-octane/toluene).

In this study soot nucleation is modelled by the collision between two pyrene molecules [25, 26] [26]:

$\dot{\omega}_{\text {nucl }} \propto\left[A_{4}\right]^{2} \sqrt{T}$

where $\left[\mathrm{A}_{4}\right]$ is the molar concentration of pyrene. The variation of $\left[\mathrm{A}_{4}\right]$ at the location of the peak nucleation rate with $X_{\text {tol }}$ is also displayed in Fig. 3(b) in the iso-octane/toluene doped flames. It is evident the molar concentration of $\mathrm{A}_{4}$ displays a synergistic effect with respect to increase in $X_{\text {tol }}$ and peaks at $X_{\text {tol }}=0.6$, which explains why $\dot{\omega}_{\text {nucl }}$ in iso-octane/toluene doped flames also peaks at $X_{\text {tol }}=0.6$.

The soot mass growth by PAH condensation is modelled by the collision between soot particles and pyrene molecules. As a consequence, it depends in a nonlinear fashion on temperature, pyrene concentration, and soot particle size. Figure 3(c) shows the variation of both $\left[\mathrm{A}_{4}\right]$ and the soot surface area density, $A_{S}$, with $X_{\text {tol }}$ at the locations where the PAH condensation rates peak in $n$-heptane/toluene doped flames. Once again, $\left[\mathrm{A}_{4}\right]$ exhibits a synergistic effect and peaks at $X_{\mathrm{tol}}=0.2$, Fig. 3(c), though $\left[\mathrm{A}_{4}\right]$ does not vary significantly with $X_{\text {tol }}$ at the location of peak PAH condensation rates. Clearly, the increase in the PAH condensation rate of soot growth with increasing $X_{\text {tol }}$ results from an increase in both $\left[\mathrm{A}_{4}\right]$ and $A_{\mathrm{S}}$. On the other hand, the soot surface area density $A_{\mathrm{S}}$ increases almost linearly with $X_{\text {tol }}$ due to enhancement in both the soot number density, $N$, and the surface area per soot particle, $A_{S p}$, 
i.e., a direct consequence of increased soot loading as more toluene is added to the fuel mixture. The non-linear effects have been found to be more pronounced in $\dot{\omega}_{\text {cond }}\left(E_{\mathrm{r}}=0.62\right.$ from Eq. (1)) than in $\left[\mathrm{A}_{4}\right]\left(E_{r}=0.44\right)$. At this point, it is useful to point out that the predicted synergistic effects in PAH concentration (here $\mathrm{A}_{4}$ ), but not in soot volume fraction, and the stronger synergistic effect of $\mathrm{A}_{4}$ in iso-octane/toluene doped flames than that in $\mathrm{n}$ heptane/toluene ones, are consistent with the findings of Choi et al. [3] in their experimental investigation of counterflow diffusion flames. Such qualitative agreement supports the notion that the present reaction mechanism and soot model are capable of capturing the overall influence of toluene content in binary doping fuel mixtures of n-heptane/toluene and isooctane/toluene on PAH and soot formation.

The soot surface growth is modelled using the HACA mechanism [26]:

$\dot{\omega}_{S G} \propto k_{4}\left[C_{2} H_{2}\right] A_{S} \chi_{C s o o t}$

where $k_{4}$ is only a function of temperature [26]. $\left[\mathrm{C}_{2} \mathrm{H}_{2}\right]$ and $\chi_{\text {Csoot }}$ are the molar concentration of acetylene and the number of de-hydrogenated sites per unit soot surface area $\left(\mathrm{cm}^{2}\right)$, given by:

$\chi_{\text {Csoot }}=\frac{\left(k_{1}\left[X_{H}\right]+k_{2}\left[X_{O H}\right]\right) \chi_{C s o o t-H}}{k_{-1}\left[X_{H 2}\right]+k_{-2}\left[X_{H 2 O}\right]+k_{4}\left[X_{C 2 H 2}\right]+k_{5}\left[X_{O 2}\right]}$

where $\left[X_{\mathrm{i}}\right]$ represents the molar concentration of species $i$. The expressions of the reaction rate constant $k_{\mathrm{i}}$ can be found in Ref. [26]. Model predictions have shown that $\left[\mathrm{C}_{2} \mathrm{H}_{2}\right]$ is almost constant at the locations of the peak HACA surface growth rate at different $X_{\text {tol }}$. The nonlinear relationship followed by the maximum value of $\dot{\omega}_{S G}$ as a function of $X_{t o l}$ can then only be due to $A_{\mathrm{S}}$ and/or $\chi_{\text {Csoot }}$. Their variations with $X_{\text {tol }}$ at the location where $\dot{\omega}_{S G}$ is maximum 
are plotted in Fig. 3(d) in $n$-heptane/toluene doped flames. The soot surface area density $A_{\mathrm{S}}$ increases monotonically and in a non-linear manner with $X_{\text {tol }}$. On the other hand, $\chi_{\text {Csoot }}$ decreases nearly linearly with $X_{\text {tol }}$ due primarily to a decrease in H radicals (not shown). It was found that the non-linearity in the product $\mathrm{A}_{S} \times \chi_{\text {Csoot }}\left(E_{r}=0.60\right)$ is slightly stronger than that in $A_{\mathrm{S}}\left(E_{r}=0.51\right)$.

The results discussed above reveal how a variation in the toluene content in the binary doping fuel mixture affects the soot formation processes. Figure 4 shows the maximum molar concentrations of benzene $\left(A_{1}\right)$, naphthalene $\left(A_{2}\right)$, phenanthrene $\left(A_{3}\right)$, and pyrene $\left(A_{4}\right)$ as a function of $X_{\text {tol }}$ in the iso-octane/toluene doped flames. The same trends can also be observed for those in the n-heptane/toluene doped flames. It is clear that the concentration of $\mathrm{A}_{4}$ displays a synergistic effect and peaks at $X_{\text {tol }}=0.6$. It should be pointed out that the variation of the maximum $\left[\mathrm{A}_{4}\right]$, Fig 4, is consistent with that observed at the location of the peak nucleation rate shown in Fig. 3(b). The variations of $\mathrm{A}_{1}$ and $\mathrm{A}_{4}$ concentrations with $X_{\text {tol }}$ display a synergistic effect, but not those of $A_{2}$ and $A_{3}$, in qualitative agreement with the experimental observations of Choi et al. made in soot formation and soot formation oxidation counterflow diffusion flames [3].

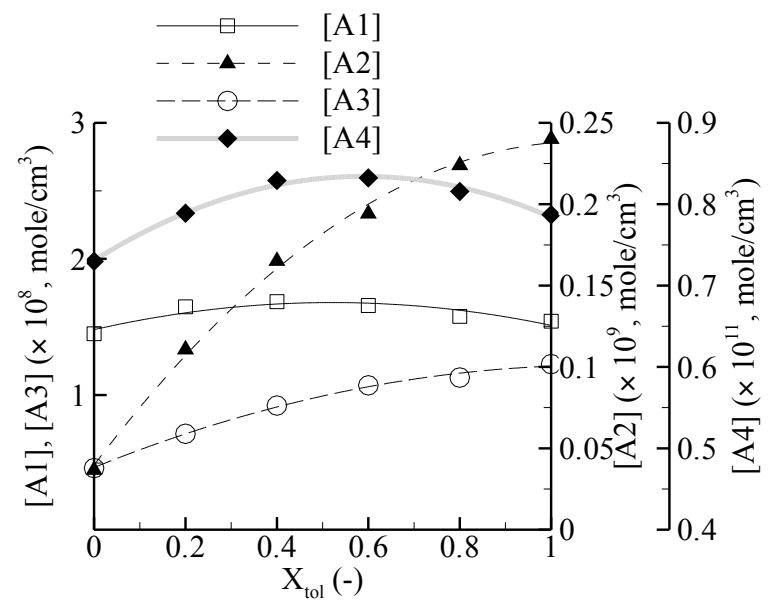

Figure 4. Variations of the peak molar concentrations of $\mathrm{A}_{1}, \mathrm{~A}_{2}, \mathrm{~A}_{3}$, and $\mathrm{A}_{4}$ with $X_{\text {tol }}$ in isooctane/toluene doped flames. 
The variation of the reaction rates of all the reactions leading to the production of $A_{1}, A_{2}, A_{3}$, and $\mathrm{A}_{4}$ as a function of $X_{\mathrm{tol}}$ has been analyzed. The following reaction

$$
\mathrm{C}_{7} \mathrm{H}_{8}+\mathrm{H} \leftrightarrow \mathrm{A}_{1}+\mathrm{CH}_{3}
$$

was found to be responsible for the synergistic effects for $A_{1}$ shown in Fig. 4. Fig. 5(a) shows the maximum normalized reaction rate in the case of the iso-octane/toluene doped flames as a function of $X_{\text {tol }}$ as well as the corresponding normalized molar concentrations for the species involved in this reaction (R0). The same behaviour also occurs in the n-heptane/toluene flames. As $X_{\text {tol }}$ increases, the molar concentration of toluene $\left(\mathrm{C}_{7} \mathrm{H}_{8}\right)$ increases monotonically, whereas that of $\mathrm{H}$ decreases monotonically. These opposite evolutions are consistent with those reported by Raj et al. [14] for the soot formation and soot formation/oxidation laminar counterflow diffusion flames and are responsible for the synergistic effects observed for $A_{1}$. The maximum reaction rate of R0 displays a synergistic effect and peaks at $X_{\text {tol }}=0.8$, Fig. $5(a)$

The formation of $\mathrm{A}_{2}$ is dominated by the following three reactions:

$$
\begin{aligned}
& 2 \mathrm{C}_{5} \mathrm{H}_{5} \leftrightarrow \mathrm{A}_{2}+2 \mathrm{H} \\
& \mathrm{A}_{2^{-}}+\mathrm{H} \leftrightarrow \mathrm{A}_{2} \\
& \mathrm{C}_{10} \mathrm{H}_{9}+\mathrm{H} \leftrightarrow \mathrm{A}_{2}+\mathrm{H}_{2}
\end{aligned}
$$

The last reaction, $R 3$, was found to exhibit a strong synergistic effect. The production of $A_{3}$ is mainly due to the following reactions:

$$
\begin{aligned}
& \mathrm{A}_{2} \mathrm{R}_{5} \text { (biphenyl) }+\mathrm{C}_{2} \mathrm{H}_{2} \rightarrow \mathrm{A}_{3} \\
& \mathrm{~A}_{2}+\mathrm{C}_{4} \mathrm{H}_{2} \rightarrow \mathrm{A}_{3} \\
& \mathrm{~A}_{3^{-}}+\mathrm{H} \leftrightarrow \mathrm{A}_{3}
\end{aligned}
$$


Model results show that there is a synergistic effect in the reaction rate of R5. Finally, the reaction

$$
\mathrm{A}_{3^{-}}+\mathrm{C}_{2} \mathrm{H}_{2} \leftrightarrow \mathrm{A}_{4}+\mathrm{H}
$$

is found largely responsible for the production of $\mathrm{A}_{4}$ and the observed synergistic effects. Figures 5(b), 5(c) and 5(d) show the variation of the maximum normalized reaction rates of $\mathrm{R} 3, \mathrm{R} 5$ and R7 and the corresponding molar concentrations of the species involved in these reactions with $X_{\text {tol }}$ for the iso-octane/toluene doped flames. The results show that, consistently with the findings of Raj et al. [14], the synergistic effects are likely to occur in the reactions in which the concentrations of the two reactants evolve oppositely with $X_{\text {tol }}$, see R0 and R7 for example. It is interesting to point out that $\mathrm{A}_{2}$ does not display a synergistic effect, Fig. 4, even though there is a strong synergistic effect in the reaction rate R3 shown in Fig. 5(b). 

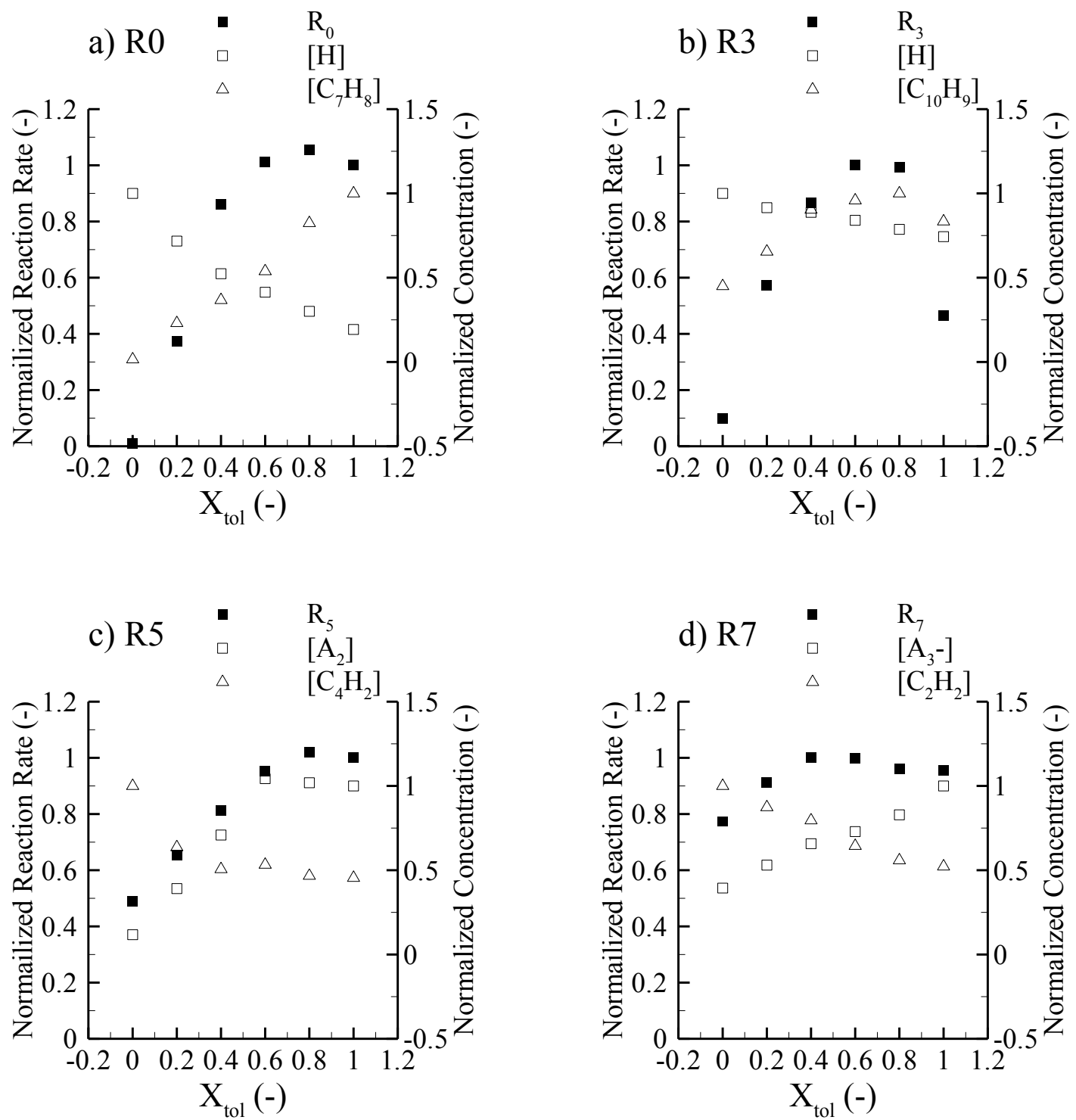

Figure 5. Normalized reaction rates and species concentrations for the main reactions responsible for the production of: (a) $A_{1}$, (b) $A_{2}$, (c) $A_{3}$, and (d) $A_{4}$. These results are for the iso-octane/toluene doped flames.

\section{Concluding remarks}

Axisymmetric laminar coflow nitrogen-diluted methane diffusion flames doped with binary mixtures of $n$-heptane/toluene and iso-octane/toluene were simulated using a fairly detailed reaction mechanism for gasoline surrogate and a PAH-based sectional soot model to gain 
insights into the influence of toluene content on soot formation. The following conclusions can be drawn:

(1) The numerical model predicts that the peak soot volume fractions in both the nheptane/toluene and iso-octane/toluene doped flames increase with increasing the toluene content in these binary doping mixtures and more soot is produced in iso-octane/toluene doped flames. These results are in qualitative agreement with experimental measurements and were obtained by using the same chemical mechanism, the same soot model, and the same set of soot model constants used in a previous study to model soot formation in $n$-heptane/isooctane doped methane diffusion flames. This model performs fairly consistent in modelling soot formation in laminar methane diffusion flames doped with any two components of the toluene reference fuels for gasoline surrogate using the hybrid reaction mechanism.

(2) The model is capable of reproducing the experimentally observed phenomena of the nonlinear increase in soot formation and the synergistic effects in benzene and pyrene production with increasing the toluene content in both the n-heptane/toluene and iso-octane/toluene doped laminar methane diffusion flames.

(3) The overall flame model failed to predict the correct soot volume fraction distributions in the diffusion flames investigated, i.e., the model predicted that the peak soot volume fraction occurs along the flame wing, while the experimental measurements indicate that the high soot volume fractions appear in the flame centerline region. Further improvements in the soot nucleation sub-model are required to take into account soot nucleation by collision of other PAH molecules in addition to pyrene.

(4) Reactions responsible for the synergistic effects of n-heptane/toluene and isooctane/toluene doping to methane on benzene (A1) and pyrene (A4) formation were found to be $\mathrm{C}_{7} \mathrm{H}_{8}+\mathrm{H} \leftrightarrow \mathrm{A}_{1}+\mathrm{CH}_{3}$ and $\mathrm{A}_{3^{-}}+\mathrm{C}_{2} \mathrm{H}_{2} \leftrightarrow \mathrm{A}_{4}+\mathrm{H}$. 


\section{References}

[1] T.C. Bond, S.J. Doherty, D.W. Fahey, P.M. Forster, T. Berntsen et al., Bounding the role of black carbon in the climate system: A scientific assessment, J. Geophys. Res.: Atmos. $118(2013) 5380-5552$.

[2] M. Krzyzanowski, B. Kuna-Dibbert, J. Schneider, Health effects of transport-related air pollution, World Health Organization www.euro.who.int/_data/assets/pdf_file/0006/74715/E86650.pdf

[3] B.C. Choi, S.K. Choi, S.H. Chung, Soot formation characteristics of gasoline surrogate fuels in counterflow diffusion flames, Proc. Combust. Inst. 33 (2011) 609-616.

[4] D. Witkowski, K. Kondo, G. Vishwanathan, D. Rothamer, Evaluation of the sooting properties of real fuels and their commonly used surrogates in a laminar co-flow diffusion flame, Combust. Flame 160 (2013) 1129-1141.

[5] M. Kashif, P. Guibert, J. Bonnety, G. Legros, Sooting tendencies of primary reference fuels in atmospheric laminar diffusion flames burning into vitiated air, Combust. Flame $161(2014) 1575-1586$.

[6] M. Kashif, J. Bonnety, A. Matynia, P. Da Costa, G. Legros, Sooting propensities of some gasoline surrogate fuels: combined effects of fuel blending and air vitiation, Combust. Flame 162 (2015) 1840-1847.

[7] A. Khosousi, F. Liu, S.B. Dworkin, N.A. Eaves, M.J. Thomson, X. He, Y. Dai, Y. Gao, F. Liu, S. Shuai, J. Wang, Experimental and numerical study of soot formation in laminar coflow diffusion flames of gasoline/ethanol blends, Combust. Flame 162 (2015) 39253933. 
[8] W.J. Pitz, N.P. Cernansky, F.L. Drier, F.N. Egolfopoulos, J.T. Farell, D.G. Friend, H. Pitsch, Development of an experimental database and chemical kinetic models for surrogate gasoline fuels, SAE 2007-01-0175 (2007), doi:10.4271/2007-01-0175.

[9] B.M. Gauthier, D.F. Davidson, R.K. Hanson, Shock tube determination of ignition delay times in full-blend and surrogate fuel mixtures, Combust. Flame 139 (2004) 300-311.

[10] J.C.G. Andrae, P. Björnbom, R.F. Cracknell. G.T. Kalghatgi, Autoignition of toluene reference fuels at high pressures modeled with detailed chemical kinetics, Combust. Flame 149 (2007) 2-24.

[11] N. Morgan, A. Smallbone, A. Bhave, M. Kraft, R. Cracknell, G. Kalghatgi, Mapping surrogate gasoline compositions into RON/MON space, Combust. Flame 157 (2010) $1122-1131$.

[12] G. Blanquart, P. Pepiot-Desjardins, H. Pitsch, Chemical mechanism for high temperature combustion of engine relevant fuels with emphasis on soot precursors, Combust. Flame 156 (2009) 588-607.

[13] C. Marchal, J. Delfau, C. Vovelle, G. Moréac, C. Mounaim-Rousselle, F. Mauss, Modelling of aromatics and soot formation from large fuel molecules, Proc. Combust. Inst. 32 (2009) 753-759.

[14] A. Raj, I.D.C. Prada, A.A. Amer, S.H. Chung, A reaction mechanism for gasoline surrogate fuels for large polycyclic aromatic hydrocarbons, Combust. Flame 159 (2012) 500-515.

[15] J.Y Hwang, W. Lee, H. G. Kang, S.H. Chung, Synergistic effect of ethylene-propane mixture on soot formation in laminar diffusion flames, Combust. Flame 114 (1998) 370380. 
[16] S.M. Lee S.S. Yoon, S.H. Chung, Synergistic effect on soot formation in counterflow diffusion flames of ethylene-propane mixtures with benzene addition, Combust. Flame $136(2004) 493-500$.

[17] S.S. Yoon , D.H. Anh, S.H. Chung, Synergistic effect of mixing dimethyl ether with methane, ethane, propane, and ethylene fuels on polycyclic aromatic hydrocarbon and soot formation, Combust. Flame 154 (2008) 368-377.

[18] P. H. Joo, Y. Wang, A. Raj, S. H. Chung, Sooting limit in counterflow diffusion flames of ethylene/propane fuels and implication to threshold soot index, Proc. Combust. Inst. 34 (2013) 1803-1809.

[19] J.L. Consalvi, F. Liu, J. Contreras, M. Kashif, G. Legros, S. Shuai, J. Wang, Numerical study of soot formation in laminar coflow diffusion flames of methane doped with primary reference fuels, Combust. Flame 162 (2015) 1153-1163.

[20] Q. Zhang, H. Guo, F. Liu, G.J. Smallwood, M.J. Thomson, Modeling of soot aggregate formation and size distribution in a laminar ethylene/air coflow diffusion flame with detailed PAH chemistry and an advanced sectional aerosol dynamics model, Proc. Combust. Inst. 32 (2009) 761-768.

[21] F. Liu, G.J. Smallwood, An efficient approach for the implementation of the SNB based correlated-k method and its evaluation, J. Quantitative Spectroscope \& Radiative Transfer 84 (2004) 465-475.

[22] N.A. Slavinskaya, P. Frank, A modelling study of aromatic soot precursors formation in laminar methane and ethane flames, Combust. Flame 156 (2009) 1705-1722.

[23] S.B. Dworkin, Q. Zhang, M.J. Thomson, N.A. Slavinskaya, U. Riedel, Application of an enhanced PAH growth model to soot formation in laminar coflow ethylene/air diffusion flame, Combust. Flame 158 (2011) 1682-1695. 
[24] J.L. Consalvi, F. Liu, Numerical study of the effects of pressure on soot formation in laminar coflow n-heptane/air diffusion flames between 1 and 10 atm, Proc. Combust. Inst 35 (2015) 1727-1734.

[25] J.Z. Wen, M.J. Thomson, M.F. Lightstone, S.N. Rogak, Detailed kinetic modeling of carbonaceous nanoparticle inception and surface growth during the pyrolysis of C6H6 behind shock waves, Energy \& Fuels 20 (2006) 547-559.

[26] J. Appel, H. Bockhorn, M. Frenklach, Kinetic modeling of soot formation with detailed chemistry and physics: laminar premixed flames of C2 hydrocarbons, Combust. Flame 121 (2000) 122-136.

[27] Y. Wang, A. Raj, S.H. Chung, Soot modeling of counterflow diffusion flames of ethylene-based binary mixture fuels, Combust. Flame 162 (2015) 586-596.

[28] P. Selvaraj, P.G. Arias, B.J. Lee, H.G. Im, Y. Wang, Y. Gao, S. Park, S.M. Sarathy, T. Lu, S.H. Chung, A computational study of ethylene-air sooting flames: effects of large polycyclic aromatic hydrocarbons, Combust. Flame 163 (2016) 427-436.

[29] A.R. Coderre, K.A. Thomson, D.R. Snelling, M.R. Johnson, Spectrally resolved light absorption properties of cooled soot from a methane flame, Appl. Phys. B. 104 (2011) 175-188. 


\section{List of figure captions}

Figure 1. Distributions of temperature in n-heptane/toluene doped flames for different $X_{\text {tol }}$.

Figure 2. Measured (top row) and computed (bottom row) distributions of soot volume fraction in $n$-heptane/toluene doped flames, (a) and (b), and in iso-octane/toluene doped flames, (c) and (d), for different $X_{\text {tol }}$.

Figure 3. Variations of the peak soot volume fractions and other soot related quantities with $X_{\text {tol }}$ : (a) peak soot volume fractions, (b) peak nucleation rates and A4 concentration, (c) peak condensation rates, A4 concentration, and soot surface area density, and (d) peak HACA surface growth rates, soot surface area density, and the number of de-hydrogenated sites.

Figure 4. Variations of the peak molar concentration of $A_{1}, A_{2}, A_{3}$, and $A_{4}$ with $X_{\text {tol }}$ in isooctane/toluene doped flames.

Figure 5. Normalized reaction rates and species concentration for the reactions responsible of the synergistic effects for the production of: a) $A_{1}$, b) $A_{2}$, c) $A_{3}$ and d) $A_{4}$. These results are for the iso-octane/toluene flames. 